\title{
Versatility of Vertical Distraction Osteogenesis and Sticky Bone in Three-Dimensional Augmentation for Atrophic Alveolar Ridge
}

\author{
Abdel Aziz B Abdullah*1, Hossam Eldin M Ali ${ }^{1}$, Amany Khalifa El-Sayed ${ }^{2}$
}

Codex : 12/2021/10

Aadj@azhar.edu.eg

\section{KEYWORDS}

Atrophic ridge,

vertical distraction osteognesis,

sticky bone, GTR, CBCT, implant.

1. Department of Oral and Maxillofacial Surgery, Faculty of Dental Medicine, (Assiut, boys), Al-Azhar University, Egypt.

2. Department of Oral and Maxillofacial Surgery, Faculty of Oral and Dental Medicine, Modern University for Technology \& Information, Egypt.

* Corresponding Author e-mail: Abdelazizbaiomy@azhar.edu.eg

\begin{abstract}
Aim. This prospective study was designed to evaluate three-dimensional (3-D) alveolar ridge augmentation through two stages surgical approach, using vertical alveolar distraction osteogenesis (VADO) followed by onlay sticky bone covered by collagenmembrane, for augmentation of the atrophic alveolar ridge to facilitate implant installation. Subjects and Methods: Ten patients with atrophic alveolar ridge were treated by VADO. After bone consolidation the distractors were removed, implants were inserted, sticky bone graft was packed at buccal aspect, and covered by guided tissue regeneration (GTR) membrane. The implants were loaded after three months of its placement. Clinical evaluation was done to assess wound healing and implant stability. Also, the following parameters were evaluated on orthopantomography and cone-beam computed tomography; relapse in the distracted bone, crestal bone loss around the implant and bone density around the implant. All data was statistical analysed. Results: Mean vertical bone gain was $6.5 \mathrm{~mm}$ (range 5-8 $\mathrm{mm}$ ), and the mean width gain was $4 \mathrm{~mm}$ ( range $3-5 \mathrm{~mm}$ ). There was $100 \%$ survival rate of all implants. There was significant decrease in the mean bone height throughout all periods. Also, significant improvement in bone density around the implant was reported along follow up periods. Conclusion: VADOfollowed by onlay sticky bone graft with GTR can be successfully performed to gain proper 3-D measurements of alveolar ridge that are essential for ideal implant installation in severe atrophic mandibular alveolar ridge.
\end{abstract}

\section{INTRODUCTION}

Alveolar ridge atrophy is one of the most common challenges that could be faced during rehabilitation of the edentulous patient by dental implant and may be associated with compromised functional and esthetic results ${ }^{(1-3)}$.

Alveolar ridge resorption phenomenon, that occurred as a result of tooth extraction or avulsion, follow a predictable pattern as the facial aspect of the alveolar ridge is the main site of resorption, which first reduces in width and later in height ${ }^{(4)}$. The rate of alveolar bone 
resorption during the first year after extraction is very rapid. The amount of bone resorption is predestined to be $40-60$ percent during the first 3 years after tooth extraction and then decreases to $0.25-0.5$ percent annual loss rate thereafter ${ }^{(5-7)}$. Ideal implant placement can be compromised by inadequate alveolar ridge height and width. Therefore, alveolar ridge reconstruction is essential step to allow ideal implant insertion and creates more esthetic profile and long-term implant stability ${ }^{(8,9)}$.

Different modalities have been used for alveolar ridge augmentation, such as autogenous or alloplastic bone grafting ${ }^{(10,11)}$,guided bone regeneration ${ }^{(12,13)}$ and vertical alveolar distraction osteogenesis (VADO) ${ }^{(14,15)}$. The main advantage of VADO is the increased alveolar bone height with new bone formation beneath the distracted bone segment. Furthermore, simultaneous lengthening of the surrounding soft tissues that achieved by histogenesis ${ }^{(16,17)}$.

Recently, for acceleration of graft healing, autologous concentrated growth factors (CGF) enriched bone graft matrix (sticky bone) using autologous fibrin glue (AFG) was developed. Sticky bone has several advantages including, its moldability,so could be adapted over various shape of bony defect and the fibrin network that entraps platelets and leukocytes releases growth factors enhancing bone and soft tissue regeneration. Also, the fibrin interconnection minimizes soft tissue ingrowth into the sticky bone graft ${ }^{(18)}$. These advantages encouraged researchers to use sticky bone combined with guided tissue regeneration (GTR) membrane or no for augmentation of narrow alveolar ridge with simultaneous placement of dental implant ${ }^{(18-20)}$.

Accordingly, the aim of the present study was to assess the efficacy of 3- dimensional alveolar ridge augmentation; through alveolar distraction to increase bone height, and sticky bone covered by GTR to improve ridge width in patients requiring implant placement in atrophic posterior mandibular region.

\section{PATIENTS AND METHODS}

\section{Patient selection:}

Patient suffering from atrophic posterior mandible and candidate to restore the missed teeth by dental implant were selected from those attending the Outpatient Clinics of Oral and Maxillofacial Surgery Department, Faculty of Dentistry, AlAzhar University. This prospective study extended from November 2015 till November 2019 year. Research procedures were explained to all the patients and they signed an informed consent form before the study. The study was conducted according to rules of ethics declared by Helsinki, and ethical committee approval was obtained from Al-Azhar ethical committee.

\section{Preoperative evaluation:}

History and clinical examination were performed for all patients to evaluate their medical and dental condition. Also, intraoral clinical examination was performed to evaluate oral hygiene, periodontal condition, amount of keratinized mucosa, and level of muscle attachment at areas planed for implant placement.

Radiographically, orthopantomogram (OPG) (Orthophos3,Sirona system) and cone beam computerized tomography (CBCT) (Kodak 9500 cone beam 3D system) were used to assess the alveolar bone height and width available for implantation (Fig.1a\&b).

\section{Inclusion criteria:}

Patients were included in this study if they were free from any local or systemic condition that may interfere with healing. Also, presented with 2-3 missing teeth at least in posterior mandibular area and $\mathrm{CBCT}$ demonstrated that ridge width ranged from $4-6 \mathrm{~mm}$ and bone height above inferior alveolar canal ranged between $8-10 \mathrm{~mm}$. 


\section{Exclusion criteria:}

Patients were excluded from this study if they suffered from any medical disease that could complicate wound healing, mucosal diseases, such as lichen planus in the areas to be treated, poor oral hygiene or heavy smoking patients.

\section{Surgical procedure:}

It consisted of 2 stages. The first stage included vertical alveolar distraction to correct ridge height and the second stage included implant insertion and horizontal augmentation.

\section{First stage:}

During stage one, all surgeries were performed under general anesthesia and complete aseptic condition. Each patient was received prophylactic antibiotic (Augmentin 1gm vial, GlaxoSmithKline, Fifth district, New Cairo, Cairo, Egypt), mouth wash (DG-wash,Al Esraa Pharmaceuticals, Fourth Industrial Zone, Badr Industrial City, Cairo, Egypt), and antiedematous (Alpha Chymotrypsin Ampule, Amoun Pharmaceutical Co., Cairo, Egypt).

In all patients we used extraosseous alveolar distractor (made by Modern Techniques Centre, Cairo, Egypt). A mucoperiosteal incision was placed on buccocrestal aspect of the ridge and a mucoperiosteal flap was raised. Extraosseous alveolar distractor was applied on the facial aspect of the ridge to prepare site of screw insertion and then removed. A Trapezoidal osteotomy of the transport segmentwas achieved by burs which were used to place marks of osteotomy lines under copious saline irrigation. The bilateral vertical bone osteotomy lines were made in anangulated manner, and a horizontal osteotomy was performed at asafe distance of $2 \mathrm{~mm}$ above inferior alveolar canal (Fig.1c). After that, saws were used under copious saline irrigation to complete the osteotomy, and complete separation of transport segment was done by thin osteotome. The distractor was placed and fixed to the basal and the osteomatized segment with monocortical 2.0 screws. The basal plate was fixed by 2 screws on either side of distraction rode while the transport plate was fixed with one screw on either side of the distraction rode (Fig.1d). Then the device was checked for mobility. After that, the wound was closed with 3 zero vicryl suture (Fig.1e).

The distractor was left in place for 7 days as latent period that followed by activation of the distractor at rate of $1 \mathrm{~mm} /$ day (at rhythm $0.5 \mathrm{~mm}$ twice), till the required bone height was obtained (slight overcorrection of 2 to $3 \mathrm{~mm}$ was performed). Then distractor left 3 months to achieve bone consolidation.

\section{Second stage:}

After completing the consolidation period, the patient returned for removal of the distractor, and instillation of implant (Superline Systems, Dentium, Co. Ltd, Suwon, South Korea). Before implant insertion sticky bone was prepared ${ }^{(18,20)}$ as follow; $10 \mathrm{~mL}$ of patient's venous blood was taken from the antecubital fossa. After that, the blood in the test tubes was centrifuged at $2700 \mathrm{rpm}$ for 2 minutes. The test tube showed 2 different layers. The upper layer is autologous fibrin glue (AFG) layerand red blood cell is collected in bottom layer which had been discarded. The upper AFG was aspirated by syringe and mixed with particulate bone powder (Bonemedic, Meta-biomed, Korea) and allowed for 5-10 minutes for polymerization in order to produce sticky bone which has a yellow color (Fig1f).

After implant instillation, sticky bone was placed on buccal aspect of alveolar ridge and was covered by collagen membrane (GENOSS, Dentium, Co. Ltd, Suwon, South Korea) (Fig.1g).

After surgical procedures, all patients received the same medications which prescribed before surgery for 5 days. Postoperative instructions for the patients included soft diet and oral hygiene with $0.2 \%$ chlorohexidine mouth rinse. The fixed prosthetic restoration of implants was performed after 3 months of osseointegration (Fig.1h). 


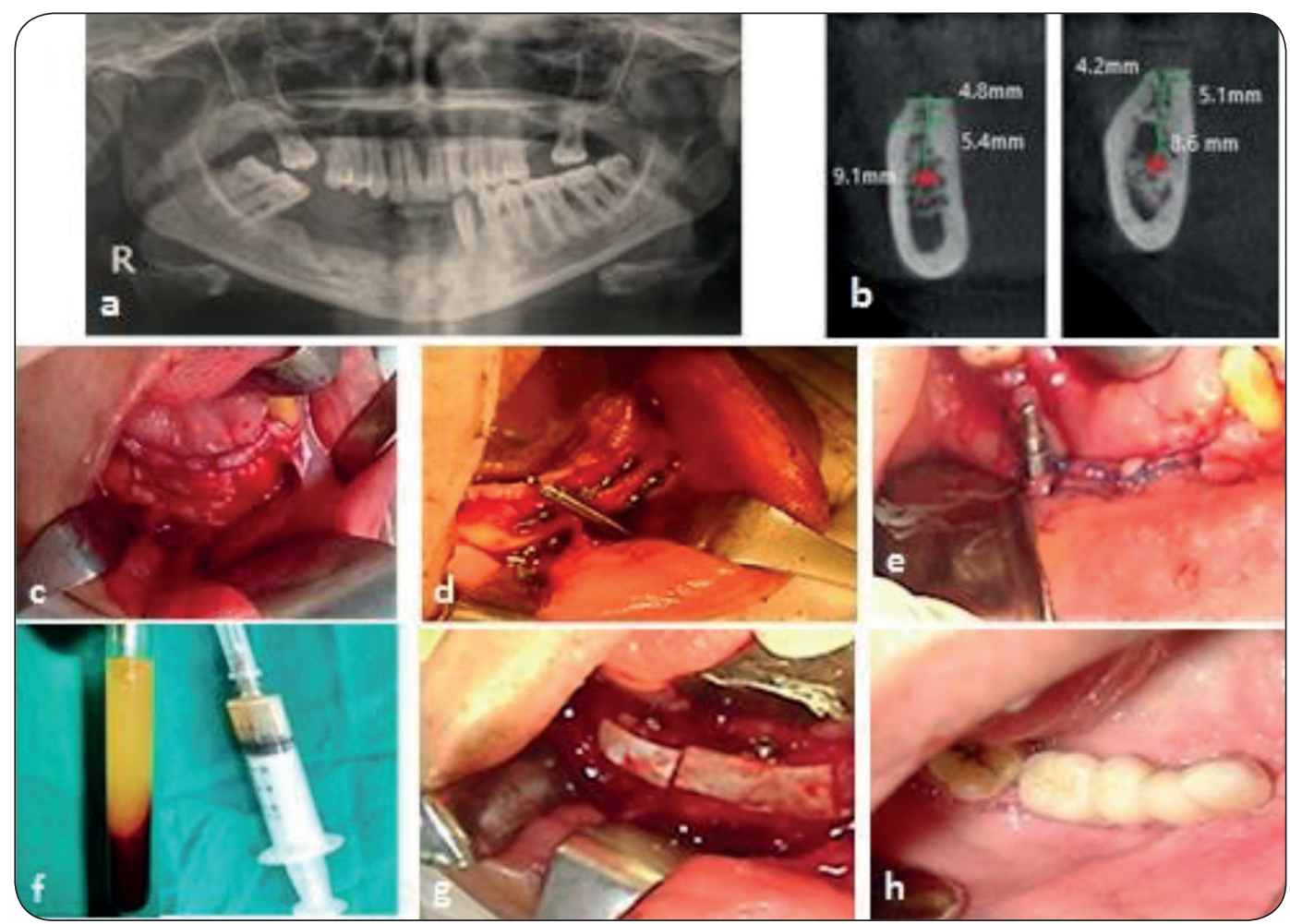

Fig. (1) (a) Preoperative OPG showing atrophic alveolar ridge (b) Preoperative measurements on CBCT (C) Intraoral photograph showing surgical approach and segmental alveolar osteotomy (d) Extraosseous alveolar distractor after fixation (e) wound closure(f) Aspiration of AFG after preparation (g) Application of sticky bone and collagen membrane after implant installation (h) Final prosthetic rehabilitation after 3 months from implant installation.

\section{Postoperative evaluation}

After both surgical stages, clinical evaluation was performed to observe signs of infection, wound dehiscence, and function of inferior alveolar nerve. Primary implant stability was recorded by using Osstell TM. Changes in Implant Stability Quotient (ISQ) values taken immediately after implant placement, at 3 months, and 6 month of implant placement. They were measured in triplicate and averaged to yield the mean baseline ISQ value for each implant.

\section{Radiographic evaluation:}

OPGs were taken immediately after placement of distractor, after completing the distractor activation (to evaluate the gain in the alveolar bone and used as reference to evaluate the relapse at the subsequent periods), after distractor removal and implant installation, and at 3 month of implant placement (to record the relapse in the augmented bone). Relapse in alveolar distraction is amount of decrease in augmented bone.

The augmented bone was measured on OPG as the distance from osteotomy line in the basal bone to the top of alveolar crest. The relapse in alveolar distraction was estimated at the end of activation period $\mathrm{T} 1$, at the end of consolidation periods $\mathrm{T} 2$, and after 3 months of implant placement T3. The amount of bone relapse could be estimated as the differences between TI and T2, and T1 and T3.

CBCT were taken immediately after implant placement (baseline), at 3 months and 6 months to evaluate the change in alveolar ridge width at different follow up periods. Also change in crestal 
bone level around dental implant was assessed on the CBCT sagittal cuts on computerized software. The distance from implant apex to a reference point at the implant surface where the marginal bone contacts the implant was measured. This was measured mesially and distally foreach implant.

Measuring of bone density: Average density was determined at the implant marginal bone using Bioquant ${ }^{\circledR}$ (G Power, Ver. 3.192 copy right 19922014). The region of Interest (ROI) was selected and traced (color density selection). Through counting of threshold pixels in each ROI, a single pixel that represents a specific color (white pixels in radiographs) is selected allowing for automatic selection of all other pixels in the ROI that threshold areas are traced and counted as a number of pixels that can be calculated as a ratio of the whole ROI.

\section{Data analysis:}

Data were coded and entered into a Microsoft excel sheet and then transferred to IBM SPSS statistical software version 21 ; for displaying a descriptive distribution of each variable including the frequency and percentage in addition to the mean and standard deviation. This was followed by comparative paired and unpaired t test were used to compare continuous variables, significance level was considered at $\leq 0.05$.

\section{RESULTS}

The study was carried on ten systemically healthy patients ( 6 female and 4 male) with mean age of $43 \pm 7$ years. The gained bone was evident clinically and radiographically. Two of them were had bilateral free end saddle (Kennedy class 1),3 patients with Kennedy class 2 and other patients were had Kennedy class 3. The mean gain in bone height was $6.5 \mathrm{~mm}$ (range 5- $8 \mathrm{~mm}$ ) and the mean gained bone width was $4 \mathrm{~mm}$ (range $3-5 \mathrm{~mm}$ ).

A total of 11 alveolar distractors ( one patient had bilateral VADO \& 9 patients had unilateral VADO) were used in this study. A total of 22 endoosseous dental implants (two in each distracted area) were placed. Implant diameter ranged from 3.6 to $4.8 \mathrm{~mm}$ and implant length ranged from 10 to $12 \mathrm{~mm}$.

In all patients healing was uneventful. Neither infection nor lymphadenitis were reported throughout the study. Two patients show wound dehiscence and plate exposure during activation of distractor, and 1 case showed wound dehiscence after $2^{\text {nd }}$ stage of surgery (sticky bone grafting). Lip paresthesia were reported in four patients after distractor placement which resolved after $8-12$ weeks later with vitamin B medication.

All patients had mucosal redness around the implant at the second day after implant placement; this redness was completely resolved one week later. On percussion all implants showed resonant sound.

\section{Changes in Implant Stability Quotient (ISQ):}

The mean value of ISQ was $49.700 \pm 4.98$ at time of implant insertion that increased to $66.55 \pm 2.66$ at 3 months, and became $69.00 \pm 3.03$ after 6 month. Statistical analysis showed highly significant difference $(0.001)$ between time of implant instillation and at 3 and 6 months and low significant difference $\mathrm{P}<0.05$ between 3 and 6 month intervals.

\section{Radiographic observations:}

OPG measurements presented that the mean bone height was $7.3 \pm 23$ mmbefore distraction and became13.6 $\pm 1.4 \mathrm{~mm}$ after distraction (T1). Then it reduced to $13.1 \pm 1.2 \mathrm{~mm}$, and $11.7 \pm 0.9 \mathrm{~mm}$ at $\mathrm{T} 2$, and $\mathrm{T} 3$ periods respectively. The mean reduction of bone height (relapse) from $\mathrm{T} 1$ to $\mathrm{T} 2$, was $0.5 \pm 0.2$ $\mathrm{mm}$, from $\mathrm{T} 2$ to $\mathrm{T} 3$, was $1.4 \pm 0.3 \mathrm{~mm}$, and from T1 to T3, was $1.9 \pm 5 \mathrm{~mm}$. Statistical analysis showed statistically significant increase of the bone height after distraction, that followed by significant decrease in the mean bone height at the subsequent follow up periods. 
Table (1) Mean and $S D$ values of reduction in bone height, and $P$ value along observation periods

\begin{tabular}{|c|c|c|c|c|}
\hline Period & $\begin{array}{c}\text { Mean } \\
\text { difference }\end{array}$ & \pm SD & t- value & P \\
\hline T1 - T2 & 0.5 & \pm 0.2 & 6.7 & $0.025^{*}$ \\
\hline T2 - T3 & 1.4 & \pm 0.3 & 2.1 & $0.001^{*}$ \\
\hline T1 - T3 & 1.9 & \pm 0.5 & 1.9 & $<0.001^{*}$ \\
\hline
\end{tabular}

* Statistically significant: $(p<0.05)$.

**High statistically significant: $(p<0.01)$.

The preoperative mean width of the alveolar ridge on CBCT was $4.825 \pm 0.706 \mathrm{~mm}$ and increased to $7.840 \pm 0.533 \mathrm{~mm}$ immediately after the surgery. Then it decreased to $6.725 \pm 0.456 \mathrm{~mm}$ and $6.640 \pm 0.435 \mathrm{~mm}$ at 3 and 6 months postoperative respectively. There was high statistically significant increase in the ridge width immediately postoperative that followed by significant reduction in the width during the subsequent periods.

Mean marginal bone loss around the implants immediately after placement was zero and increased into $10.010 \pm 0.460 \mathrm{~mm}$ after 3 months, then elevated to became $1.040 \pm 0.380$ after 6 months. There was no significant loss of crestal bone level around dental implant at the end of the study.

Immediately after implant insertion mean bone density was $371.6 \pm 150.08 \mathrm{HU}$ and increased to $613.7 \pm 177.94 \mathrm{HU}$ and $914.0 \pm 296.36 \mathrm{HU}$ at 3 and 6 months after implantation respectively. There was highly statistically significant increased bone density $(\mathrm{p}<0.001)$ between different intervals.

Table (2) Comparison between, ISQ, MBL, BD scores \& Alveolar ridge width measurements at different periods

\begin{tabular}{|c|c|c|c|c|c|c|c|c|c|c|c|c|}
\hline & \multicolumn{4}{|c|}{$\begin{array}{c}\text { Immediate after implant insertion } \\
\text { VS. } 3 \mathrm{~m}\end{array}$} & \multicolumn{4}{|c|}{$\begin{array}{c}\text { Immediate after implant insertion } \\
\text { VS. } 6 \mathrm{~m}\end{array}$} & \multicolumn{4}{|c|}{$3 \mathrm{~m} \mathrm{VS.} \mathrm{6m}$} \\
\hline & \multicolumn{2}{|c|}{ t value } & \multicolumn{2}{|c|}{$\mathbf{P}$} & \multicolumn{2}{|c|}{ t value } & \multicolumn{2}{|c|}{$\mathbf{P}$} & \multicolumn{2}{|c|}{ t value } & \multicolumn{2}{|c|}{$\mathbf{P}$} \\
\hline ISQ & \multicolumn{2}{|c|}{7.11} & \multicolumn{2}{|c|}{$0.0001 * *$} & \multicolumn{2}{|c|}{16.960} & \multicolumn{2}{|c|}{$0.001 * *$} & \multicolumn{2}{|c|}{2.92} & \multicolumn{2}{|c|}{$0.015 *$} \\
\hline $\begin{array}{l}\text { Marginal } \\
\text { bone loss }\end{array}$ & \multicolumn{2}{|c|}{6.531} & \multicolumn{2}{|c|}{$0.001 * *$} & \multicolumn{2}{|c|}{7.107} & \multicolumn{2}{|c|}{$0.001 * *$} & \multicolumn{2}{|c|}{1.643} & \multicolumn{2}{|c|}{0.121} \\
\hline \multirow[t]{3}{*}{$\begin{array}{c}\text { Bone } \\
\text { Density }\end{array}$} & \multicolumn{2}{|c|}{11.117} & \multicolumn{2}{|c|}{$0.001 * *$} & \multicolumn{2}{|c|}{11.055} & \multicolumn{2}{|c|}{$0.001 * *$} & \multicolumn{2}{|c|}{6.472} & \multicolumn{2}{|c|}{$0.001 * *$} \\
\hline & \multicolumn{2}{|c|}{$\begin{array}{l}\text { PreoperativeVS. } \\
\text { Immediate after } \\
\text { implant Insertion }\end{array}$} & \multicolumn{2}{|c|}{$\begin{array}{l}\text { PreoperativeVS. } \\
3 \text { m }\end{array}$} & \multicolumn{2}{|c|}{$\begin{array}{l}\text { PreoperativeVS. } \\
6 \mathrm{~m} \mathrm{~m}\end{array}$} & \multicolumn{2}{|c|}{$\underset{6 m}{3 m V S .}$} & \multicolumn{2}{|c|}{$\begin{array}{c}\text { Immediate } \\
\text { after implant } \\
\text { insertionVS. } \\
3 \text { months }\end{array}$} & \multicolumn{2}{|c|}{$\begin{array}{c}\text { Immediate } \\
\text { afterimplant } \\
\text { insertion VS. } \\
6 \text { months }\end{array}$} \\
\hline & t value & $\mathbf{P}$ & $t$ value & $\mathbf{P}$ & t value & $\mathbf{P}$ & t value & $\mathbf{P}$ & t value & $\mathbf{P}$ & t value & $\mathbf{P}$ \\
\hline $\begin{array}{l}\text { Alveolar } \\
\text { ridge width }\end{array}$ & 25.586 & $0.001^{*}$ & 23.680 & $0.001 * *$ & 20.105 & $0.001 * *$ & -1.039 & 0.312 & -2.558 & $0.019^{*}$ & -3.365 & $0.003 *$ \\
\hline
\end{tabular}

*Statistically significant: $(P<0.05)$

**High statistically significant: $(P<0.01)$. 

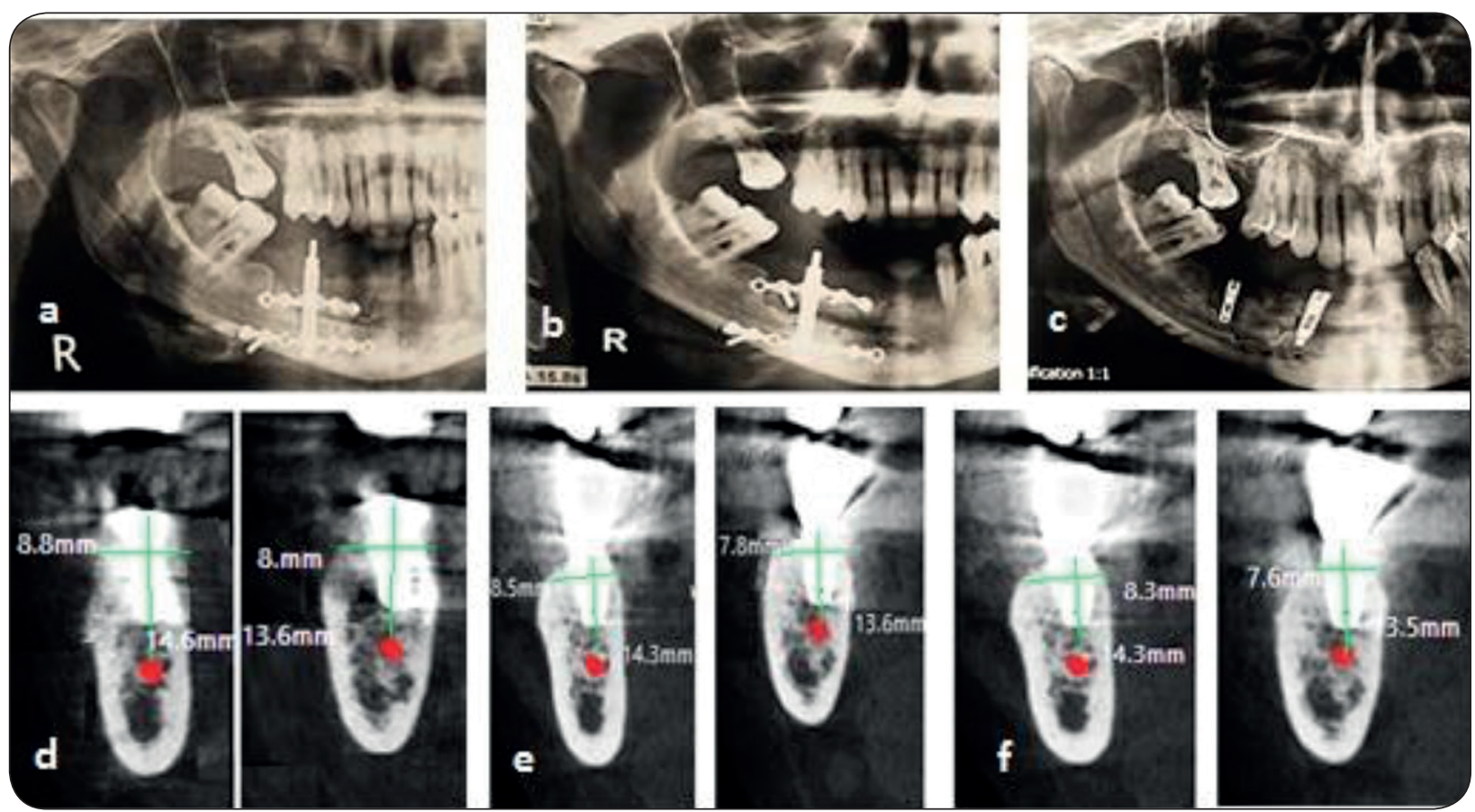

Fig. (2) Postoperative OPG at different intervals (a) Immediately after osteotomy and distractor fixation (b) after distraction (c) after consolidation period. Postoperative CBCT at different intervals after implant insertion and bone grafting (d) Immediately (e) at 3 months ( f) after 6 monthsv

\section{DISCUSSION}

Alveolar ridge deficiency could limit the esthetical and functional outcomes of implant rehabilitation and, it might compromise long term implant success rate. In these cases, bone augmentation is performed to gain enough bone volume. Adequate bone volume is mandatory to provide patients with proper inter-arch relations and an adequate crownto-root ratio for superior prosthetic results ${ }^{(3-21)}$.

Several reconstructive and regenerative methods have been used foraugmentation of mandibular alveolar ridge including inferior alveolar nerve (IAN) lateralization to allow placement of long implants in this region. However, mental nerve paraesthesia has been reported ${ }^{(6)}$. Another method is to place short implants above IAN. This technique compromises load-bearing capacity of such implant ${ }^{(5,7)}$. Neither of these techniques resolves the problem of excessive length of the crown. Another approach is autologous bone grafting, but such grafts are subjected to resorption, limited to soft tissue tolerance and associated with donor site morbidity ${ }^{(8,9)}$.
Alveolar distraction osteogenesis provides natural formation of bone in the distracted chamber in a relatively short time. This eliminates the need for autogenous bone graft and allow a shortening of treatment time. Soft tissues can follow the elongation of the underlying bone, and there is a lower risk of infection of the surgical site (0\% in this study) as compared to grafts on GBR (Chiapasco et $\mathrm{al}^{(22,23)}$ ).

Present study described new technique for 3-D augmentation in vertically andhorizontally deficient alveolar ridge cases. Through benefiting from aforementioned advantages of VADO in vertical augmentation, and regenerative preoperative of combined using for sticky bone with GTR in horizontal augmentation of alveolar ridge.

In our study, preoperative ridge height more than $8 \mathrm{~mm}$ was essential to perform VADO. This was in the same side with Rachmiel et al. ${ }^{(21)}$ technique, who described that the minimal height of $6 \mathrm{~mm}$ for the crestal transported segment is essential to achieve 
fixation of the distraction device and to avoid fracture of the segment.Also, it is essential to perform safe distance of $2 \mathrm{~mm}$ of bone abovemandibular canal to maintain inferior alveolar nerve.

In the present study, VADO protocol involved 7 days latency period, activation of distraction devices at rate of $0.5 \mathrm{~mm}$ twice daily until reach to desired height, and 3 months for consolidation. This is in agreement with standard protocol which described by several authors ${ }^{(24,25)}$.

In a review by Saulacic et al. ${ }^{(24)}$, it was shown that a 7-day latency period provide good bone quality and allows gingival/mucosal healing. Regarding the activation rate different studies ${ }^{(22,26,27)}$ concluded that the standard activation rate $1 \mathrm{~mm} \backslash$ day at rhythm $0.5 \mathrm{~mm}$ twice. In opposite side, Rachmiel et al. ${ }^{(21)}$ used $0.5 \mathrm{~mm} /$ day (activation) for vertical elongation in their study. Explanation of that a latency period was 4 days in their study.

In this study, the consolidation period was 3 months. This is in agreement with other investigation $^{(25,28)}$. This explained by histological study of Chiapasco et $\mathrm{al}^{(28)}$ which demonstrated that 3 months following mandibular distraction showed woven bone reinforced by parallel-fiber bone undergoing maturation.

In contrast to Quereshy et al ${ }^{(29)}$ article which enumerated different applications of CBCT in oral and maxillofacial surgery. Our study used OPG to evaluate bone formation and height gait during VADO while CBCT was used for evaluation bone quality and quantity after implant installation. This to decrease number of CBCT done and avoid artifacts which may be occurred due to distractor device presence. Where, repeated and high doses of CBCT is harmful. This is in agreement with Gang $\mathrm{Li}^{(30)}$, and Abd-Elaal et $\mathrm{al}^{(31)}$.

Pérez-Sayáns et al. ${ }^{(25)}$ review reported that the mean height gain was greater with extraosseous distraction devices in contrast with intraosseous ones, ranging from 8.13 to $6.97 \mathrm{~mm}$. Saulacic et $\mathrm{al}^{(32)}$ found a mean gain of $6.88+2.52 \mathrm{~mm}$. These results are in accordance with our results. In the present study, the amount of reduction in the distracted area (relapse in ADO) at the end of consolidation period (T2) was $0.5 \pm 0.2 \mathrm{~mm}$, and at 6 months after implantation (T3) was $1.9 \pm 0.5 \mathrm{~mm}$. There was significant decrease in the mean bone height throughout all periods. This is in accordance with the results of Saulacic et al ${ }^{(32)}$ and Kim et $\mathrm{al}^{(33)}$. Which demonstrated that after vertical alveolar distraction, 3 to $20 \%$ of the gained vertical bone may undergo relapse. Therefore, we performed a slight overcorrection of 2 to $3 \mathrm{~mm}$. This is in agreement with Rachmiel et $\mathrm{al}^{(21)}$ who recommended an overcorrection of $15-20 \%$ to overcome relapse of distracted segment.

In current study, dental implant installation was performed at the same surgery of distractor removal and accompanied with horizontal augmentation of the ridge using sticky bone and GTR. This is in accordance with Kim et al. ${ }^{(33)}$ and Pérez-Sayáns et $\mathrm{al}^{(34)}$ studies.

In the current study, the mean increase in alveolar ridge width was $4 \mathrm{~mm}$. Also, there was no complication such as infection, inflammation or lip paresthesia after bone grafting procedure. Only one case of wound dehiscence was reported that was healed over couple of days through application of good oral hygiene measures. This is in accordance with Roy et al. ${ }^{(35)}$ who demonstrated that the use of PRF matrix effectively induce endothelial cell proliferation and improved wound angiogenesis in chronic wound.

Mean crestal bone loss around the dental implant was $1.040 \pm 0.380$ at 6 months after implant placement. This is in agreement with Adell et al. ${ }^{(36)}$ who reported $1.5 \mathrm{~mm}$ marginal bone loss around dental implants during the first year. Also in accordance with Lobo et al. ${ }^{(37)}$ and Sohn et al. ${ }^{(18)}$ who demonstrated that mixture of PRF with biphasic bioceramics facilitates cell attachment, proliferation and differentiation which in turn provides more 
biocompatible, osteoconductive and osteoinductive combination leading to more new bone formation.

Regarding mean values of bone density around dental implant material, there was marked increase in bone density along follow up intervals.This is in agreement with Ozemir et al ${ }^{(38)}$ who stated that the use of PRF can increase the quality (density) of the newly formed bone and enhance the rate of new bone formation and this may be explained by the presence of concentrated growth factor in the PRF which is in agreement with our result

According to our results VADO combined with sticky bone and GTR is a technique with greater potential in vertical and horizontal gain. The performance of dental implants has a success and survival rate like dental implants placed on bones that does not need bone augmentation techniques. Their results indicated that alveolar distraction offers more predictable long-term results for vertical-height bone than other methods. On the other hand, Enislidis et al. ${ }^{(39)}$ reported that the use of subperiosteal devices for vertical augmentation of edentulous mandibles is hazardousand offers no advantage over other surgical methods and that all of the patients had severe complications. We have not observed serious complications in our study. It is may be because of careful selection of patients, proper treatment planning, and using concentrated growth factor matrix in our study.

\section{CONCLUSION}

From our results can concluded that 3-D alveolar ridge augmentation through two stages surgical approach, using VADO followed by implant installation and onlay sticky bone covered by GTR membrane proved to be associated with high success rate and limited complication. It has been evidenced that the generated bone by distraction osteogenesis can withstand the biomechanical demands of implant loading. Sticky bone not only enhances the rate of new bone formation, but also increases the density of the newly formed bone around dental implant.
Funding: None.

Conflicts of interest: There are no conflicts of interest

\section{REFERENCES}

1. Ustun Y, Eeon E, Toroglu MS, Akova T. Multidisciplinary approach for the rehabilitation of dentoalveolar trauma. J Dent Traumatol 2004;20: 293-9.

2. Schropp L, Wenzel A, Kostopoulos L, Karring T. Bone healing and soft tissue contour changes following singletooth extraction: a clinical and radiographic 12- month prospective study. Int J Periodontics Restorative Dent. $2003 ; 23: 313-23$.

3. Chappuis, V., Engel, O., Reyes, M., Shahim, K., Nolte, L. P., \& Buser, D. Ridge alterations post-extraction in the esthetic zone: A3D analysis with CBCT. J Dent Res 2013, 92, 195-201.

4. Atwood DA. Reduction of residual ridges: A major oral disease entity. J Prosth Dent 1971; 26: 266-79.

5. Ashman A. Postextraction ridge preservation using synthetic alloplast. J Implant Dent 2000; 9:168-76.

6. Ostler M, Kokich V. Alveolar ridge changes in patients congenitally missing mandibular second premolars. J. Prosth Dent 1994; 71:144-9.

7. Fu JH,Wang HL. Horizontal bone augmentation; the decision tree. Int J Periodontics Restorative Dent 2011; 31:429-36

8. Schliephake H, Dard M, Plank H, Hierlemann H, Stern U. Alveolar ridge repair using resorbable membrane and autogenous bone particles with simultaneous placement of implants. An experimental Pilot study in dogs. Int J Oral Maxillofac Implants 2000; 15:364-73.

9. Zahrani A. Augmentation in Two Stages of Atrophic Alveolar Bone Prior to Dental Rehabilitation: A Case Report. J Contemp Dent Pract. 2007 ;8:57-63.

10. Schwartz-Arad D, Levin L. Intraoral autogenous block onlay bone grafting for extensive reconstruction of atrophic maxillary alveolar ridges. J Periodontol 2005;76:636-41 .

11. Felice P, Pistilli R, Lizio G, Pellegrino G, Nisii A, Marchetti C. Inlay versus onlay iliac bone grafting in atrophic posterior mandible: A prospective controlled clinical trial for the comparison of two techniques. Clin Implant Dent Relat Res 2009;11:69- 82 
12. Caplanis N, Sigurdsson TJ, Rohrer MD, Wikesjö UME. Effect of allogeneic, freeze- dried, demineralized bone matrixon guided bone regeneration in supraalveolar periimplant defects in dogs. Int J Oral Maxillofac Implants 1997;12:634-42.

13. Jensen OT, Greer RO JR, Johnson L, Kassebaum D. Vertical guided bone-graft augmentation in a new canine mandibular model. Int $\mathrm{J}$ Oral Maxillofac Implants 1995;10:335-44.

14. Chin M, Toth B. Distraction osteogenesis in maxillofacial surgery using internal devices: review of five cases. J Oral Maxillofac Surg 1996;54:45-53.

15. Hwang SJ, Jung JG, Jung JJ, Kyung SH. Vertical alveolar bone distraction at molar region using lag screw principle. J Oral Maxillofac Surg 2004;62:787-94

16. Garcia A, Martin-Somoza M, Gandara-Vila P, Meceiras JL. Minor complications arising in alveolar distraction osteogenesis. J Oral Maxillofac Surg 2002;60:496- 501.

17. Van Strijen P, Breuning K, Becking A, Perdijk FB, Tuinzing D. Complications in bilateral mandibular distraction osteogenesis using internal devices. Oral Surg Oral Med Oral Pathol Oral Radiolo Endod 2003;96:392-7.

18. Sohn S, Huang B, Kim J, Park E, Park C. Utilization of Autologous Concentrated Growth Factors (CGF) Enriched Bone Graft Matrix (Sticky Bone) and CGF- enriched Fibrin Membrane in Implant Dentistry. J Impl Adv Clin Dent 2015;7(10);11-29

19. EL Moheb Mohamed. "The Use of Growth Factors Fibrin Network to Enhance Architecture, Mechanical and Biological Aspect of the Graft Particles". I J Pre Clin Dent Res 2014;1:41-4.

20. Intini G. The use of platelet-rich plasma in bone reconstruction therapy. J Bioma 2009;30:4956-66.

21. Rachmiel A, Shilo D, Aizenbud D, Emodi O. Vertical Alveolar Distraction Osteogenesis of the Atrophic Posterior Mandible Before Dental Implant Insertion. J Oral Maxillofac Surg 2017,75:1164-75.

22. Chiapasco M, Romeo E, Casentini P, Rimondini L: Alveolar distraction osteogenesis vs. vertical guided bone regeneration for the correction of vertically deficient edentulous ridges :A 1-3-year prospective study on humans. Clin Oral Implants Res 2004;15:82.

23. Chiapasco M, Zaniboni M, Rimondini L: Autogenous onlay bone grafts vs. alveolar distraction osteogenesis for the correction of vertically deficient edentulous ridges: A 2-4-year prospective study on humans. Clin Oral Implants Res 2007;18:432.

24. Saulacic N, Iizuka T, Martin MS, et al: Alveolar distraction osteogenesis: a systematic review. Int J Oral Maxillofac Surg 2008;37:1-7

25. Pérez-Sayáns M, Martínez-Martín JM, ChamorroPetronacci C, Gallas-Torreira M, Marichalar-Mendía X, García- García A. 20 years of alveolar distraction: A systematic review of the literature. Med Oral Patol Oral Cir Bucal. 2018 ;23:742-51.

26. Sezer B, Koyuncu BO, Gunbay T, Sezak M. Alveolar distraction osteogenesis in the human mandible: a clinical and histomorphometric study. Implant Dent. 2012;21:317-22.

27. Mohanty R, Kumar NN, Ravindran C. Vertical Alveolar Ridge Augmentation by Distraction Osteogenesis. J Clin Diagn Res. 2015;9:43-6.

28. Chiapasco M, Lang NP, Bosshardt DD: Quality and quantity of bone following alveolar distraction osteogenesis in the human mandible. Clin Oral Implants Res 2006; 17:394-402.

29. Quereshy F, Savell T, Palomo J. Applications of Cone Beam Computed Tomography in the Practice of Oral and Maxillofacial Surgery. J Oral Maxillofac Surg 2008; 66:791-6.

30. Gang Li. Patient radiation dose and protection from conebeam computedtomography. Imaging Science in Dentistry 2013; 43: 63-9.

31. Abd-Elaal1 A, El-Mekawii H, Saafan A, El Gawad L, El-Hawary Y, Abdelrazik A. Evaluation of the effect of low level diode laser therapy applied during the bone consolidation period following mandibular distraction osteogenesis in the human. Int. J. Oral Maxillofac. Surg. 2015; 44: 989-97.

32. Saulacic N, Zix J, lizuka T: Complication rates and associated factors in alveolar distraction osteogenesis: A comprehensive review. Int J Oral Maxillofac Surg 2009; 38:210.

33. Kim J, Cho M, Kim S, Kim M. Alveolar distraction osteogenesis versus autogenous onlay bone graft for vertical augmentation of severely atrophied alveolar ridges after 12 years of long-term follow-up. Oral Surg Oral Med Oral Pathol Oral Radiol. 2013;116:540-9

34. Perez-Sayans M, Leon-Camacho Mde L, Somoza-Martin JM, Fernandez-Gonzalez B, Blanes-Vazquez-Gundin S, Gandara-Rey JM, et al. Dental implants placed on bone 
subjected to vertical alveolar distraction show the same performance as those placed on primitive bone. Med Oral Patol Oral Cir Bucal. 2013;18: 686-92.

35. Roy S, Driggs J, Ehgharably H, Biswas S, Findley M, Khanna S, et al. Platelet rich fibrin matrix improves wound angiogenesis via inducing endothelial cell proliferation. Wound Repair Regen. 2011;19:753-66

36. Adell, R., Eriksson, B., Lekholm, U., Branemark, P., Jemt, T. A long-term follow- up study of osseointegrated implants in the treatment of totally edentulous jaws. Int J Oral \& Maxillofac Impl. 1990; 5: 347-359.
37. Lobo S, Wykrota F, Oliveira A, Kerkis I, Mahecha G, Alves H. Quantification of bone mass gain in response to the application of biphasic bioceramics and platelet concentrate in critical-size bone defects. J Mater Sci Mater Med. 2009;20:1137-47.

38. Ozdemir H, Ezirganli S, Isa Kara M, Mihmanli A, Baris E. Effects of platelet rich fibrin alone used with rigid titanium barriers. Arch Oral Biol. 2013;58:537-44.

39. Enislidis G, Fock N, Ewers R. Distraction osteogenesis with subperiosteal devices in edentulous mandibles. Br J Oral Maxillofac Surg 2005;43:399-03. 
مجلة أسيوط لطب الأسنان

النشر الرسمي لكلية طب الأسنان جامعة الأزهر أسيوط الراطة

مصر

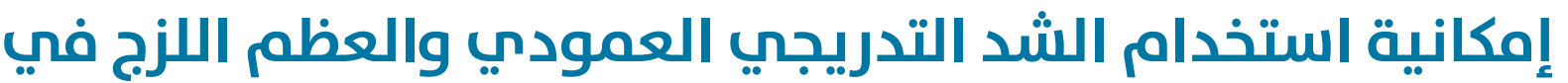 التزويد ثلاثي الابعاد للحافة التدريجة السنخيه الضامره
}

\author{
عبد العزيز بيومى عبدالله1*، حسام الدين محمد على1، أماني خليفه السيد2

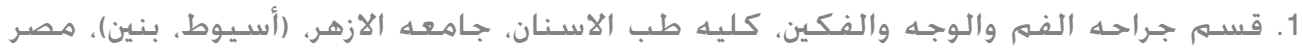

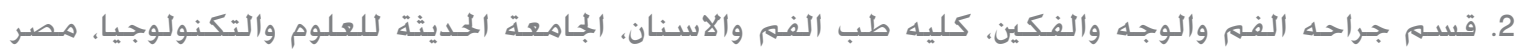 \\ ABDELAZIZBAIOMY@AZHAR.EDU.EG البريد الإلكترونين
}

الملخص :

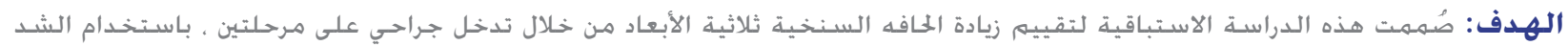

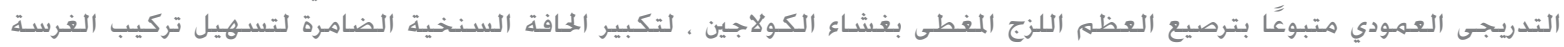

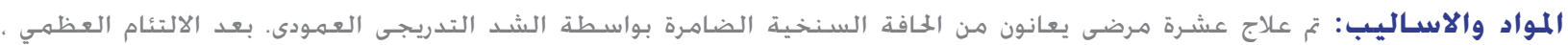

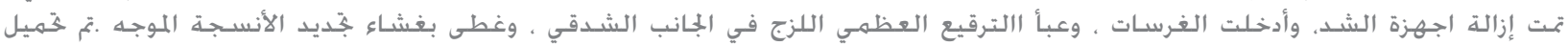

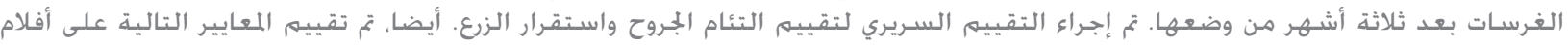

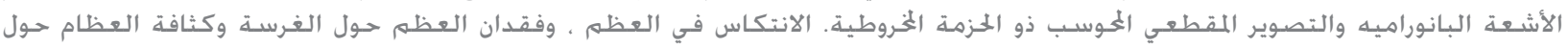
الغرسـة. تم خليل جميع البيانات إحصائياً.

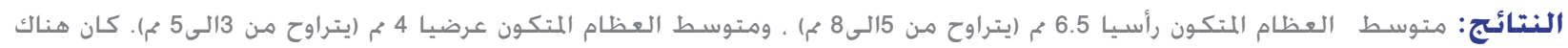

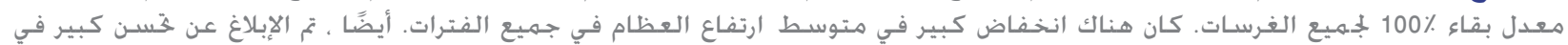
كثافة العظام حول الزرع على طول فترات المتابعة.

الخلاصة: يمكن إجراء الشد التدريجى العمودى متبوعًا بطعم عظمي لزج مع غشاء الكولاجين بنجاح للحصول على قياسات ثلاثية الأبعاد

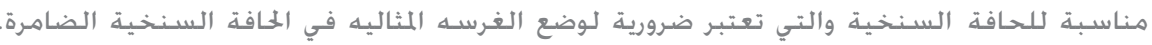

الكلمات المفتاحية: الحافه السنخيه الضامره، الشد التدريجي العمودى ،العظم اللزج، غشـاء جُديد الأنسجة الموجه، الأشعة المقطعية الخخروطية ،غرسه سنيه. 